Article

\title{
Comparative Study of Physicochemical and Antibacterial Properties of ZnO Nanoparticles Prepared by Laser Ablation of Zn Target in Water and Air
}

\author{
Ekaterina A. Gavrilenko ${ }^{1}$, Daria A. Goncharova ${ }^{1}$, Ivan N. Lapin ${ }^{1}$, Anna L. Nemoykina ${ }^{2}$, \\ Valery A. Svetlichnyi ${ }^{1, *}$, Ali A. Aljulaih ${ }^{3,4}$, Neli Mintcheva ${ }^{3,5}$ (D) and Sergei A. Kulinich ${ }^{3,4,6, *(D)}$ \\ 1 Siberian Physical Technical Institute, Tomsk State University, Lenina, 36, Tomsk 634050, Russia; \\ gavrilenko2470@gmail.com (E.A.G.); dg_va@list.ru (D.A.G.); 201kiop@mail.ru (I.N.L.) \\ 2 Laboratory of Biopolymers and Biotechnology, Tomsk State University, Lenina, 36, Tomsk 634050, Russia; \\ nemoykina@rambler.ru \\ 3 Institute of Innovative Science and Technology, Tokai University, Hiratsuka, Kanagawa 259-1259, Japan; \\ ali.aljulaih@gmail.com (A.A.A.); nnmintcheva@mgu.bg (N.M.) \\ 4 Department of Mechanical Engineering, Tokai University, Hiratsuka, Kanagawa 259-1259, Japan \\ 5 Department of Chemistry, University of Mining and Geology, 1700 Sofia, Bulgaria \\ 6 Research Institute of Science and Technology, Tokai University, Hiratsuka, Kanagawa 259-1259, Japan \\ * Correspondence: svet@spti.tsu.ru (V.A.S.); skulinich@tokai-u.jp (S.A.K.); Tel.: +7-3822-531-591 (V.A.S.); \\ +81-463-58-1211 (ext. 4893) (S.A.K.)
}

Received: 7 December 2018; Accepted: 3 January 2019; Published: 8 January 2019

\begin{abstract}
Here, we report on $\mathrm{ZnO}$ nanoparticles (NPs) generated by nanosecond pulsed laser (Nd:YAG, $1064 \mathrm{~nm}$ ) through ablation of metallic $\mathrm{Zn}$ target in water and air and their comparative analysis as potential nanomaterials for biomedical applications. The prepared nanomaterials were carefully characterized in terms of their structure, composition, morphology and defects. It was found that in addition to the main wurtzite $\mathrm{ZnO}$ phase, which is conventionally prepared and reported by others, the sample laser generated in air also contained some amount of monoclinic zinc hydroxynitrate. Both nanomaterials were then used to modify model wound dressings based on biodegradable poly L-lactic acid. The as-prepared model dressings were tested as biomedical materials with bactericidal properties towards S. aureus and E. coli strains. The advantages of the NPs prepared in air over their counterparts generated in water found in this work are discussed.
\end{abstract}

Keywords: pulsed laser ablation in water; pulsed laser ablation in air; $\mathrm{ZnO}$ nanoparticles; biomedical materials; PLLA-scaffold; antibacterial properties

\section{Introduction}

Because of their unique physicochemical properties, nanomaterials have recently attracted a lot of research interest as materials and components for various applications. Zinc oxide $(\mathrm{ZnO})$ is a wide-bandgap semiconductor of the II-VI group $\left(\mathrm{E}_{\mathrm{g}}=3.3 \mathrm{eV}\right)$ [1,2]. Of all known metal-oxide semiconductors, it is probably the most extensively studied material with applications in numerous fields, such as optoelectronics, piezoelectronics, spintronics, solar energy, gas sensing, bio-sensing, UV-blue diodes, and photocatalysis, just to name several [1-6]. Because of its high surface energy, its nanoparticles (NPs) are able to generate various reactive oxygen species (ROS), which makes such NPs efficient bacteria inhibitors that are attractive for biomedical use, as well. Having low toxicity, $\mathrm{ZnO}$ nanomaterials, unlike those of many other semiconductor oxides, can be applied to problems 
such as water, working surface and wound disinfection, as well as in food industry, and hence the number of studies on potential use of $\mathrm{ZnO}$ nanomaterials keeps growing quite fast nowadays [1-6].

There are many approaches to preparing ZnO NPs, including, for example, hydrothermal methods, chemical deposition from gas phase, microwave and sonochemical approaches, numerous sol-gel-based methods, and so on [1-3]. One attractive method to produce so-called "pure" ZnO nanostructures (i.e., with surface free of any impurities or stabilizers) for biomedical use is based on pulsed laser ablation (PLA) of metallic Zn target in different media (mainly in liquids) [4-10]. The method uses pulsed lasers (with different pulse energy and pulse width) to ablate zinc target and produce species which then react with the surrounding liquid and form $\mathrm{ZnO}$ NPs. The formation mechanisms are quite complex, depending on laser pulse parameters and composition of liquid medium, and involve several fast stages that overlap and compete with each other, such as: absorption of irradiation, melting and evaporation on the target, expansion of the formed plasma/vapor, chemical reactions and quenching by the liquid, formation of clusters and primary NPs, and secondary irradiation of the formed NPs by laser beam, just to name the main ones. Thus, when applied in liquid phase, the method combines both "top-down" and "bottom-up" synthesis approaches, as the target gets broken down by the laser beam into very small species (particles, clusters, atoms, radicals, ions), after which such species get oxidized and quenched to ambient temperature as ZnO NPs [7,9]. In addition to PLA in liquids [4-10], more recently, the PLA approach in gases or vacuum has also been applied in nanomaterial preparation, including Zn-based NPs [11,12]. In the case of PLA in air [13]: (1) target surface temperature increases, reaching melting and vaporization points; (2) plasma is formed due to interaction between the laser pulse and vaporized material; (3) ZnO NPs are formed in the plasma plume as a result of reactions between excited zinc species and ionized oxygen molecules from air, as well as outside the plume due to diffusion, where plasma ions interact with unexcited oxygen molecules. Finally, the formed $\mathrm{ZnO}$ NPs are deposited onto the substrate.

The characteristics of laser-produced ZnO NPs were found to depend on both laser parameters (wavelength, frequency, pulse energy, energy fluence, and pulse duration) and on target and ablation medium (vacuum, gas, or liquid). The effect of liquid on the physicochemical properties of generated $\mathrm{ZnO}$ NPs has been extensively studied, with the main media used being based on water, water-ethanol mixtures, $\mathrm{H}_{2} \mathrm{O}_{2}$, alkali and acidic solutions, salts and various surfactants [4-10,14-16]. The produced NPs were reported to have different shapes, such as rods, spheres, flakes, dendrites, spindles, also including additional phases, such as $\beta-\mathrm{Zn}(\mathrm{OH})_{2}$, metallic zinc, zinc peroxide $\mathrm{ZnO}_{2}$, or having core@shell morphology Zn@ZnO as a result of incomplete oxidation of metallic zinc [8,14-16].

The PLA-generated NPs were reported to demonstrate high reactivity, and unique optical, catalytic and antibacterial properties, which is often explained by their structural and surface defects [4-8,10,14-16]. The defectiveness of various ZnO NPs has been extensively analyzed, as various defects are known to provide different functionalities to $\mathrm{ZnO}$ materials $[6,14,17,18]$. Similar to other II-VI semiconductors, $\mathrm{ZnO}$ tends to have deficiencies in its anion sub-lattice, which leads to the formation of oxygen vacancies $\left(V_{O}\right)$ with low formation energy, interstitial zinc $\left(\mathrm{Zn}_{\mathrm{i}}\right)$ and zinc atoms in oxygen sub-lattice $\left(Z \mathrm{n}_{\mathrm{O}}\right)$, as well as defects such as interstitial oxygen $\left(\mathrm{O}_{\mathrm{i}}\right)$ and oxygen in the zinc sub-lattice $\left(\mathrm{O}_{\mathrm{Zn}}\right)$, the latter defects requiring high energies $[15,17]$. In their comparative study, Goto and co-workers showed that PLA in pure water mainly generated $\mathrm{ZnO}$ NPs with $\mathrm{O}_{\mathrm{i}}$ defects, while NPs prepared in pure ethanol were rich in $Z n_{i}-V_{Z n}$ defects, which was explained by the stronger oxidation ability of water [15]. At the same time, no information on defect composition of ZnO NPs PLA prepared in air has been reported thus far.

The present work aimed at preparing ZnO NPs by means of PLA in water and air and comparing their composition, structure, and properties. The materials were then incorporated into polymeric tissues based on poly L-lactic acid (PLLA) used as scaffold, where their antibacterial behavior against two different bacteria strains was evaluated and compared. 


\section{Materials and Methods}

\subsection{Preparation of $\mathrm{ZnO} N$ Ps Using PLA Method}

In this study, all nanomaterials were obtained by means of a nanosecond pulsed laser (Nd:YAG type, LOTIS TII, model LS-2131M-20, Minsk, Belarus) that ablated metallic Zn targets (purity 99.5\%) using the following parameters: $1064 \mathrm{~nm}, 20 \mathrm{~Hz}, 7 \mathrm{~ns}$, and $150 \mathrm{~mJ} /$ pulse (as wavelength, frequency, pulse width and pulse energy, respectively). Two somewhat different setups were used, as presented in Figure 1.

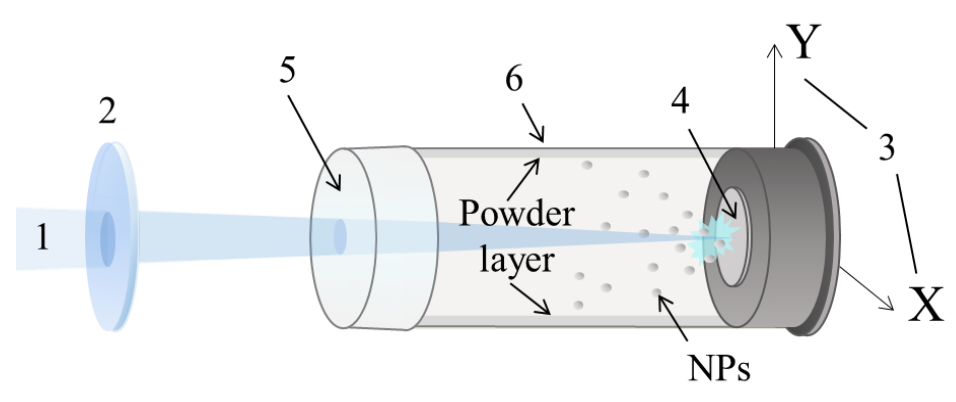

(a)

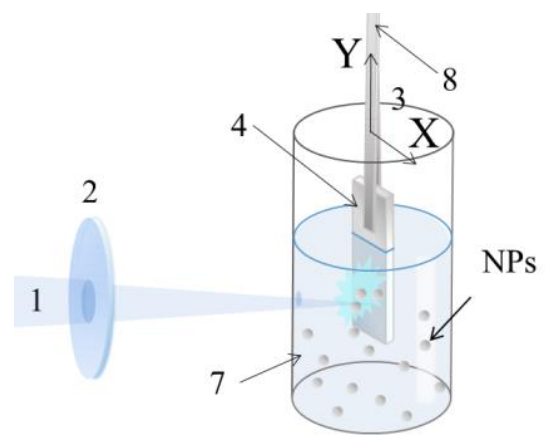

(b)

Figure 1. Setups used in the present study for PLA in air (a) and water (b). 1: laser beam; 2: focusing lens; 3: movement direction for target; 4 : $\mathrm{Zn}$ target; 5 : polyethylene membrane; 6 : cylindric reactor: 7: distilled water; 8: target holder.

For experiments in air, target with a diameter of $30 \mathrm{~mm}$ and thickness of $10 \mathrm{~mm}$ was fixed onto the back wall of a cylindrical quartz reactor filled with ambient air (see Figure 1a). The reactor was $200 \mathrm{~mm}$ in length, its internal diameter being $45 \mathrm{~mm}$, and its volume being $\sim 300 \mathrm{~cm}^{3}$. The wall of the reactor was made of polyethylene membrane which is transparent for the irradiation used. The laser beam was focused on the target surface by a long-focus $(F=500 \mathrm{~mm})$ collecting lens. The produced NPs precipitated on the reactor walls forming a powdery layer. The whole ablation procedure took $3 \mathrm{~h}$, during which the target was slowly moved along the vertical direction. The powder was then mechanically removed from the walls, and the collected sample was denoted as $\mathrm{ZnO}$ _air.

To prepare $\mathrm{ZnO}$ nanostructures in liquid phase, a zinc plate target $\left(40 \times 15 \times 10 \mathrm{~mm}^{3}\right.$ in size) was immersed into a cylindrical glass reactor filled with distilled water. The laser irradiation was focused by a short-focus $(\mathrm{F}=50 \mathrm{~mm}$ ) lens, with the beam entering the reactor through its sidewall, as seen in Figure $1 \mathrm{~b}$. To enhance NP oxidation, air was bubbled through the water by a compressor. The ablation time was $2 \mathrm{~h}$, after which the produced colloid was centrifuged and dried in air at $50{ }^{\circ} \mathrm{C}$. The ablation and separation procedures were repeated several times to collect a sufficient amount of nanomaterial. Hereafter, the sample produced in water is denoted as $\mathrm{ZnO}_{-}$water.

In both cases, the initial power density on the target surface was estimated to be around $250 \mathrm{MW} / \mathrm{cm}^{2}$. To maintain uniform irradiation of the target surface, thus providing uniform and constant ablation, the target was automatically moved both horizontally and vertically in the XY plane normal to incident beam. In both cases, the average material production rate observed after experiments was $\sim 40 \mathrm{mg} / \mathrm{h}$. More detailed description of similar experiments both in liquid and air have previously been published elsewhere [18].

\subsection{Preparation of $\mathrm{ZnO}-\mathrm{PLLA}$ Composites}

As a model material for bandage tissues with antibacterial properties, we chose biodegradable polymer poly L-lactic acid (PLLA), which easily decays upon hydrolysis and fermenting processes giving rise to non-toxic compounds. PLLA is also known to be biocompatible, which makes it an excellent candidate for pharmaceutical and biomedical applications [19]. Using the previously 
reported methodology based on electrospinning [20], PLLA scaffold was prepared and then kindly supplied to us by Drs. S. Tverdokhlebov and E. Bolbasov (Tomsk Polytechnic University).

The abovementioned nanopowders of $\mathrm{ZnO}$ (samples $\mathrm{ZnO}$ _air and $\mathrm{ZnO}$ _water) were dispersed in distilled water by means of sonication, so that the concentration of materials was $1 \mathrm{~g} / \mathrm{L}$ in both cases. Pieces of PLLA scaffold, $10 \times 10 \mathrm{~cm}^{2}$ in size and $250 \mu \mathrm{m}$ thick, were placed on a net where they were homogenously fed with colloidal solutions with ZnO NPs by means of a pump. The NP-loaded scaffolds were then dried with air at $20^{\circ} \mathrm{C}$, after which the procedures were repeated until the loading level of $1 \mathrm{mg} / \mathrm{cm}^{2}$ was achieved. Thus, two samples were obtained that consisted of PLLA scaffolds loaded with ZnO NPs of two types with the same loading (composite samples referred to as $\mathrm{ZnO}$ _water_PLLA and ZnO_air_PLLA below). To confirm whether the loaded NPs were strongly attached to the PLLA matrix, the prepared composites were washed with distilled water and the obtained water was further analyzed using UV-vis spectroscopy. No intense absorption of ZnO NPs was detected, implying good adhesion of ZnO NPs on the PLLA fibers.

\subsection{Characterization of Nanopowders and ZnO-PLLA Composites}

The crystal structure of the samples was analyzed by X-ray diffractometry (XRD), for which a XRD 6000 model (from Shimadzu, Kyoto, Japan) was used. The samples were analyzed with CuK $\alpha$ irradiation $(\lambda=1.54056 \AA)$ at a sampling rate of $0.02^{\circ} / \mathrm{s}$ and in the range of $2 \theta$ from 10 to $70^{\circ}$. Phase identification and quantitative analysis of XRD patterns were conducted using the database PDF4 and PowderCell 2.4 software (from BAM, Berlin, Germany). The morphology and size of NPs were studied by transmission electron microscopy (TEM, model CM 12 from Philips, Eindhoven, The Netherlands) with accelerating voltage of $120 \mathrm{kV}$. Drops of freshly prepared dispersions were placed onto copper grids coated with carbon film and then dried at room temperature. The surface morphology of PLLA scaffolds loaded with ZnO NPs was studied by scanning electron microscopy (SEM, model VEGA 3 SBH from Tescan, Brno, Czech Republic).

The specific surface area of the prepared powder samples was evaluated by using a standard Brunauer-Emmett-Teller procedure (low-temperature adsorption/desorption of nitrogen) in a TriStar II 3020 analyzer (Micromeritics, Norcross, GA, USA). The samples were degassed at $200{ }^{\circ} \mathrm{C}$ for $2 \mathrm{~h}$ prior to the measurements in a VacPrep 061 station (Micromeritics, Norcross, GA, USA).

UV-Vis absorption spectra of both powder samples and ZnO-PLLA composites were examined by the diffuse-reflection spectroscopy (DRS) technique on a Cary 100 spectrophotometer (Varian, Australia) with accessory DRA-CA-30I (Labsphere, North Sutton, NH, USA) in the range of 200-800 nm. As reference samples, $\mathrm{MgO}$ powder and as-supplied (i.e., unloaded with $\mathrm{ZnO}$ ) PLLA scaffold were used. Reflection spectra were converted using the Kubelka-Munk transformation approach. The obtained absorption spectra were used to evaluated the bandgap values $\left(E_{g}\right)$ of the $\mathrm{ZnO}$ nanomaterials, for which they were replotted in the $(\mathrm{F}(\mathrm{R}) \mathrm{h} v)^{n}$ versus $\mathrm{E}(\mathrm{eV})$ coordinates and the absorption edge was then extrapolated onto the absciss axis (where $y=0$ ) in accordance with the Tauc method [21]. Here $n$ depends on the nature of electronic transition and is $1 / 2$ for indirect and 2 for direct semiconductors with crystalline structure. For $\mathrm{ZnO}, n=2$ as it is a direct semiconductor. Photoluminescence (PL) spectra of the samples were recorded at room temperature by means of a Fluorolog 3-22 spectrometer (Horiba, Jobin Yvon, Edison, NJ, USA) with an excitation wavelength of $350 \mathrm{~nm}$. Fourier-transform infrared (FTIR) spectra were registered by a Nicolet 6700 spectrometer (Thermo Fisher Scientific, Waltham, MA, USA). Raman shift spectra were collected by an InVia (Renishaw, Gloucestershire, UK) Raman spectrometer, while the second harmonic of Nd:YAG laser $(\lambda=532 \mathrm{~nm})$ was used as the excitation source.

Zeta potential values of the NPs were determined through electrophoretic light scattering with phase analysis (PALS) using a Nano Brook Omni instrument (Brookhaven, NY, USA). Titration was done with aqueous $\mathrm{KOH}$, prior to which $\mathrm{ZnO}$ dispersions in water $(0.1 \mathrm{~g} / \mathrm{L})$ were sonicated for $10 \mathrm{~min}$. 


\subsection{Antibacterial Activity of NPs}

The antibacterial activity of the prepared inorganic-organic composites as model wound dressing materials was tested in accordance with the standard ISO 20743:2013 [22] and by using two bacteria strains: (1) gram-positive Staphylococcus aureus (S. aureus, test strain ATCC 25923) and (2) gram-negative Escherichia coli (E. coli, test strain B-6954, Russian Collection of Microorganisms). Both loaded with NPs and as-supplied (ZnO-free) PLLA scaffolds were cut to samples with sizes $3 \times 5 \mathrm{~cm}^{2}$ for testing. Bacteria cultures $(0.2 \mathrm{~mL})$ with concentration of $10^{5} \mathrm{CFU} / \mathrm{mL}$ in nutrient broth (diluted 20 times with distilled water) were placed onto each PLLA sample. Immediately after contact, as well as after $24 \mathrm{~h}$, the tested objects were rinsed with $20 \mathrm{~mL}$ of physiological solution for $5 \mathrm{~min}$. The obtained liquid was placed into a Petri dish containing $100 \mathrm{~mL}$ of beef-extract agar (also known as meat-and-peptone agar, MPA), and the obtained material was then cultivated at $37^{\circ} \mathrm{C}$ for $24 \mathrm{~h}$. The quantity of grown microorganisms was counted in cultures extracted after the contact with both control ( $\mathrm{ZnO}$-free) and NP-modified PLLA samples after cultivation, which permitted to determine the death percentage of tested microorganisms. The values of antibacterial activity A were determined using Formula (1):

$$
A=\left(\lg C_{t}-\lg C_{0}\right)-\left(\lg T_{t}-\operatorname{Ig} T_{0}\right)=F-G,
$$

where $F=\left(\lg C_{t}-\lg C_{0}\right)$ is the growth rate on the control (ZnO-free) PLLA sample; $\lg C_{t}$ is the average decimal logarithm of the number of bacteria found on three control samples incubated for $24 \mathrm{~h} ; \lg _{0}$ the average decimal logarithm of the number of bacteria observed on three control samples immediately upon seeding with bacteria; $G=\left(\lg T_{t}-\lg T_{0}\right)$ the growth rate on the sample loaded with antibacterial NPs; $\lg T_{t}$ the average value of decimal logarithm of the number of bacteria observed after incubation for $24 \mathrm{~h}$ on three treated samples; and $\lg \mathrm{T}_{0}$ the average decimal logarithm of bacteria number observed immediately after bacteria seeding on three PLLA samples loaded with $\mathrm{ZnO}$.

\section{Results and Discussion}

\subsection{XRD Data}

Figure 2 exhibits XRD patterns of the laser-produced samples $\mathrm{ZnO}_{-}$water (blue line) and $\mathrm{ZnO}$ _air (red) and compares them with XRD data for metallic $\mathrm{Zn}$ and $\mathrm{ZnO}$, both taken from databases (black lines). Both samples are clearly seen to demonstrate intense peaks at $2 \theta=31.68^{\circ}, 34.34^{\circ}, 36.17^{\circ}$, $47.48^{\circ}, 56.51^{\circ}, 62.78^{\circ}, 66.27^{\circ}, 67.85^{\circ}$ and $69.00^{\circ}$, implying the presence of wurtzite $\mathrm{ZnO}$ (PDF4 Card no. 04-007-9805) as dominating phase. This is consistent with previous reports on ZnO NPs prepared via PLA in liquids $[5,6,10,15,16]$, confirming that highly active $\mathrm{Zn}$ species generated by laser pulse react with oxygen and/or water molecules, giving rise to $\mathrm{ZnO}$ nanomaterial. The FWHM values of XRD peaks in pattern of sample $\mathrm{ZnO}$ _air were found to be larger than those of sampe $\mathrm{ZnO}$ _water, which is explained by smaller NP sizes of the former. Small amounts of metallic zinc were also detected in the samples, as very weak peaks at $2 \theta=43.19^{\circ}$ (PDF4 Card no. 01-071-4620), the signal being somewhat stronger in the sample produced in air than in its counterpart generated in water. This observation is also in agreement with previous studies as small amounts of metallic phase inclusion was previously reported by different groups for various $\mathrm{ZnO} N \mathrm{NPs}$ produced in liquids $[6,14,16]$.

In addition to the diffraction peaks of $\mathrm{ZnO}$, the sample produced in air exhibited a series of small peaks in the range $2 \theta=10-30^{\circ}$ (see inset in Figure 2). The latter peaks were indexed as monoclinic zinc hydroxynitrate $(\mathrm{ZHN}), \mathrm{Zn}_{5}(\mathrm{OH})_{8}\left(\mathrm{NO}_{3}\right)_{2} \times 2 \mathrm{H}_{2} \mathrm{O}$, whose pattern (PDF4 Card no. 01-072-0627) is also given in the inset for convenience. Previously, this phase was reported in NPs generated via laser ablation of $\mathrm{Zn}$ foil immersed into aqueous solution of zinc nitrate [23]. In the present study, the formation of $\mathrm{ZHN}$ is explained by interaction of laser-induced plasma with $\mathrm{Zn}$ species (atoms, ions, radicals, clusters) and air components, such as molecules $\left(\mathrm{N}_{2}, \mathrm{O}_{2}, \mathrm{H}_{2} \mathrm{O}\right)$ and excited species $\left(\mathrm{N}^{*}\right.$, $\left.\mathrm{NO}^{*}, \mathrm{NO}_{2}{ }^{*}, \mathrm{OH}^{*}\right)$. It is very likely that zinc nitrate $\mathrm{Zn}\left(\mathrm{NO}_{3}\right)_{2}$ is one of intermediate products of such reactions. It should be noted here that no formation of $\mathrm{ZHN}$ is observed as a result of atmospheric 
corrosion of metallic Zn, which supports the efficiency of PLA in preparing metastable phases. More detailed phase compositions of the $\mathrm{ZnO}$ samples, as well as their specific surface area and NP sizes, are presented in Table 1.

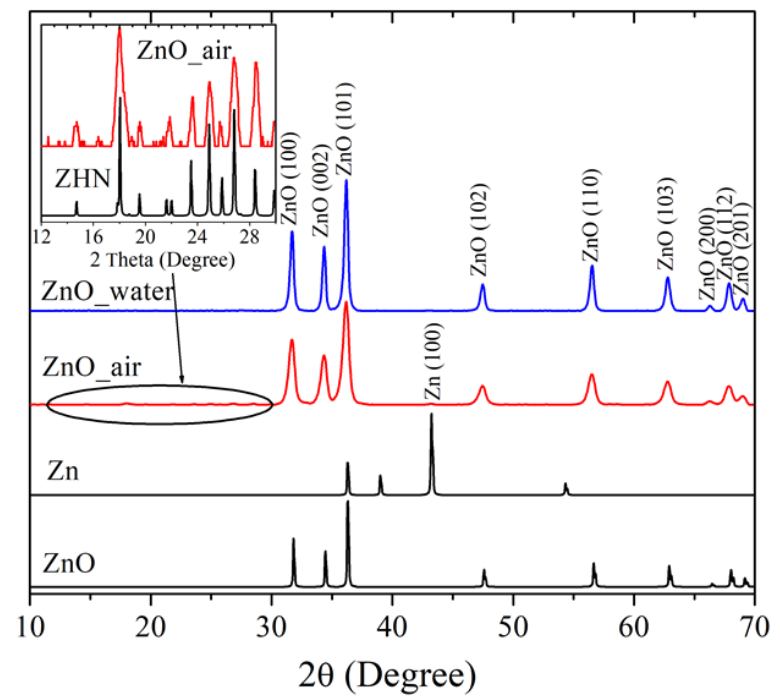

Figure 2. XRD patterns of PLA-prepared samples $\mathrm{ZnO}$ _water (blue), ZnO_air (red), and $\mathrm{Zn}$ and $\mathrm{ZnO}$ patterns from database (black). Inset shows pattern of sample $\mathrm{ZnO}$ _air and that of $\mathrm{ZHN}$ phase in a narrower range of $2 \theta$ between $12^{\circ}$ and $30^{\circ}$.

Table 1. Structural characteristics and specific surface area values of prepared samples.

\begin{tabular}{|c|c|c|c|c|c|c|}
\hline \multirow{2}{*}{ Sample } & \multicolumn{2}{|c|}{ Phase Composition } & \multirow{2}{*}{$\begin{array}{l}\text { Surface Area } \\
\left(\mathrm{m}^{2} / \mathrm{g}\right)\end{array}$} & \multicolumn{3}{|c|}{ NPs Average Size Parameters (nm) } \\
\hline & Name & $\%$ & & Diameter (nm) & Length (nm) & Width (nm) \\
\hline \multirow{3}{*}{$\mathrm{ZnO}$ air } & $\mathrm{ZnO}$ & 92 & \multirow{3}{*}{$36 \pm 4$} & \multirow{3}{*}{$18-26$} & \multirow{3}{*}{-} & \multirow{3}{*}{-} \\
\hline & $\mathrm{ZHN}$ & 7 & & & & \\
\hline & $\mathrm{Zn}$ & 1 & & & & \\
\hline \multirow{2}{*}{ ZnO_water } & $\mathrm{ZnO}$ & $>99$ & \multirow{2}{*}{$20 \pm 2$} & \multirow{2}{*}{$12-21$} & \multirow{2}{*}{ 30-100 } & \multirow{2}{*}{$14-20$} \\
\hline & $\mathrm{Zn}$ & $<1$ & & & & \\
\hline
\end{tabular}

Thus, the XRD measurements indicate that the nanomaterial obtained in water was mainly $\mathrm{ZnO}$ with trases of metallic Zn, while the NPs prepared in air had a few per cent of ZHN.

\subsection{Microscopic Observations}

\subsubsection{TEM Images}

According to the TEM image of sample ZnO_air in Figure 3a, the material prepared in air consisted of NPs with different shapes: spheres, nanocubes, and polyhedrons (see insets in Figure 3a), with average sizes being 18-26 nm. Meanwhile, sample ZnO_water had mainly nanorods as its main component (Figure $3 b$ ). Since $\mathrm{ZnO}$ is well-known to be a high-surface-energy material if no surfactant is available, its NPs prepared in water at elevated temperatures were previously reported to agglomerate and recrystallize into nanorods [16,24]. Similarly shaped ZnO NPs were previously reported by Honda et al. [16] who ablated $\mathrm{Zn}$ in water with millisecond pulsed laser and explained nanorod formation by an increase in temperature during PLA. Another group also produced $\mathrm{ZnO}$ nanorods by PLA of $\mathrm{Zn}$ in water by means of nanosecond pulsed laser followed by heat treatment of the formed colloid at $60-80^{\circ} \mathrm{C}$ [24]. In this study, we also used no surfactant when ablating in water, and thus some increase in temperature during PLA (and secondary irradiation of the initial ZnO NPs) could lead to their recrystallization into nanorods. ZnO NPs are known to have various shapes as 
the phase has no symmetry center in its crystal lattice [25]. This may explain the variety of shapes observed in Figure $3 \mathrm{a}$ as the NPs produced in air had no chance to agglomerate and recrystallize as nanorods.

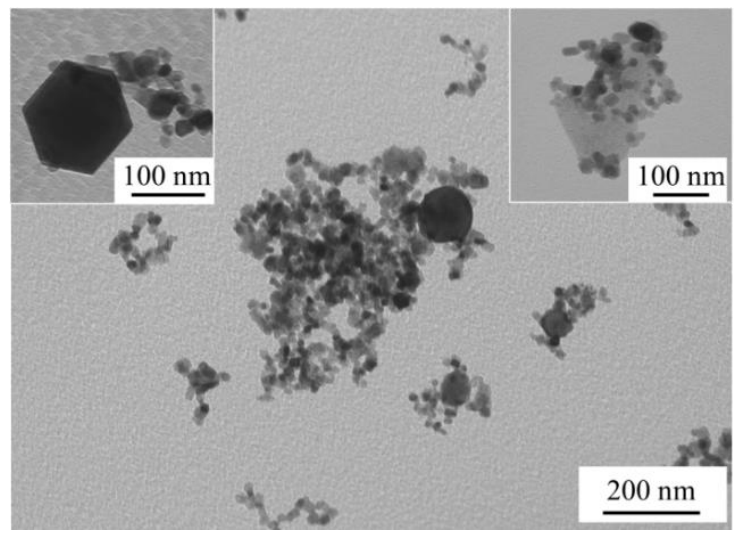

(a)

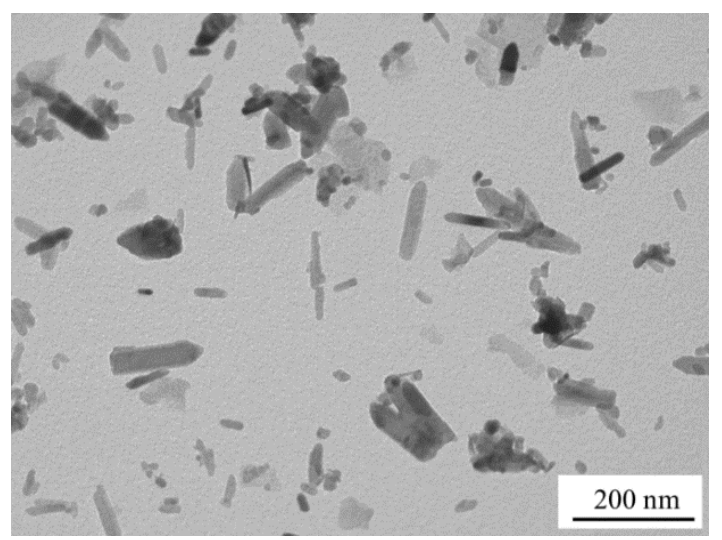

(b)

Figure 3. TEM images of samples: $\mathrm{ZnO}$ _air (a) and $\mathrm{ZnO} \_w a t e r(b)$.

The sizes and shapes of NPs exhibited in Figure 3 correlate well with the results of BET measurements. The specific surface area of the smaller NPs produced in air is seen in Table 1 to be 1.8 times larger compared with their counterparts obtained in water. It is also worth noting one more time that the rod-shaped morphology and somewhat bigger sizes of the NPs presented in Figure $3 \mathrm{~b}$ are results of secondary growth processes taking place in water after their initial formation.

\subsubsection{SEM Images of ZnO-PLLA Scaffolds}

The surface morphology of PLLA scaffolds, both as-supplied and modified by ZnO NPs, was studied by SEM, with images of samples $\mathrm{ZnO}$ _water_PLLA (a) and ZnO_air_PLLA (b) being presented in Figure 4. It can be clearly seen in Figure 4 that both types of ZnO NPs are distributed quite uniformly over the scaffold surface. At the same time, the NPs obtained in water are seen in panel (a) to be somewhat more agglomerated, while those prepared in air cover the PLLA matrix somewhat more homogeneously. This can be explained by better dispersibility of sample $\mathrm{ZnO}$ _air in solvent prior to its loading onto the PLLA scaffold.

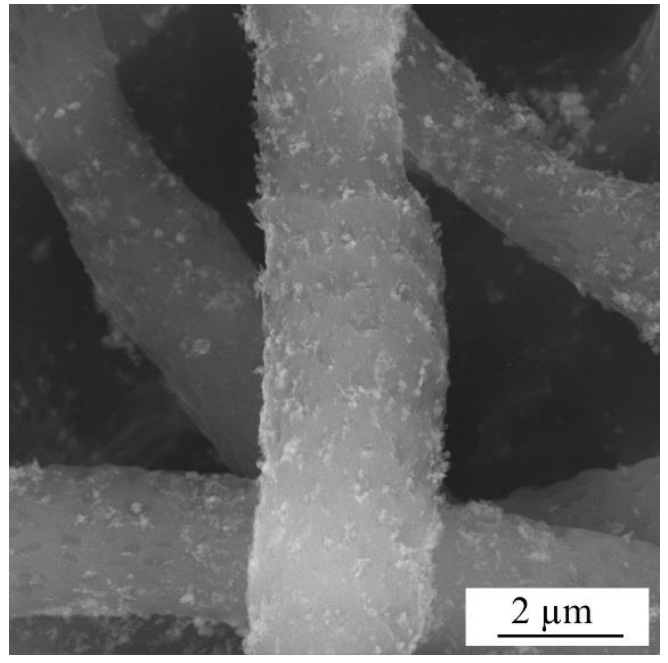

(a)

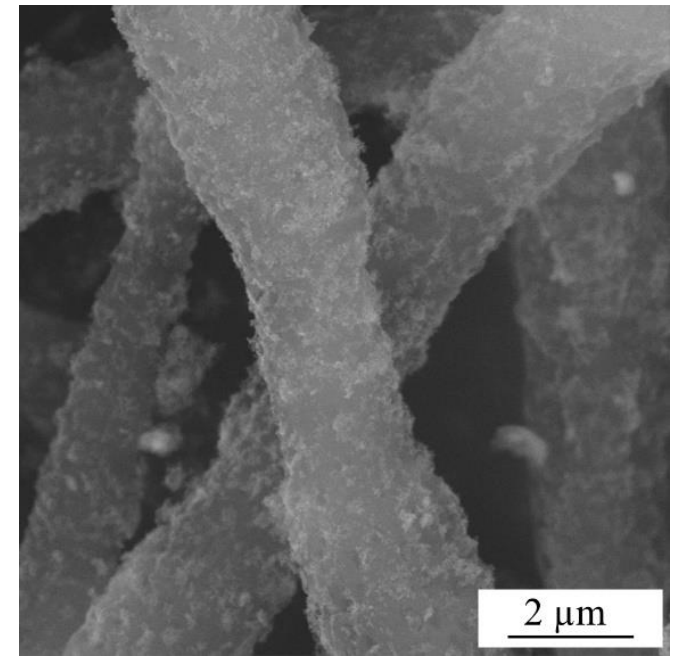

(b)

Figure 4. SEM images of model wound dressing tissues based on PLLA scaffold loaded with ZnO_water (a) and ZnO_air (b) NPs. 
The uniform NP distribution on the PLLA fibers and good adhesion were believed to be achieved owing to electrostatic interaction forces between the fibers and ZnO NPs. Polymer fibers of PLLA produced by electrospinning are known to have a high negative surface charge [26], while the laser-generated ZnO NPs possess positive surface charge, as will be described below in Section 3.4.

\subsection{Spectroscopic Data}

\subsubsection{UV-Vis Spectra}

The absorption spectra of both powder samples are presented in Figure 5a. Similarly, Figure 5b exhibits absorption spectra of PLLA scaffolds loaded with the same NPs. The wurtzite ZnO phase is known to possess a characteristic shoulder of exciton absorption in the UV range below $\sim 400 \mathrm{~nm}$, which results from the electron transfer from the valence zone (formed by $\mathrm{Zn}(3 \mathrm{~d})$ and $\mathrm{O}(2 \mathrm{p}$ ) orbitals) to the conductance zone (formed by $\mathrm{Zn}(4 \mathrm{~s})$ orbitals) [1,25]. This absorption band is observed at room temperature because of the high binding energy of excitons [1,17]. Both samples, $\mathrm{ZnO}$-water (blue

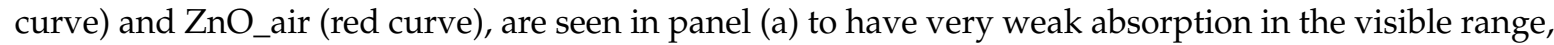
which is believed to result from admixtures (such as metallic $\mathrm{Zn}$, carbonate species, and so on). It is because of such admixtures that sample $\mathrm{ZnO}$ _water was of grayish color. When the powders were loaded onto a polymer scaffold, the obtained composite materials are seen in panel (b) to demonstrate very similar spectra (compare blue and red curves in Figure $5 a, b)$.

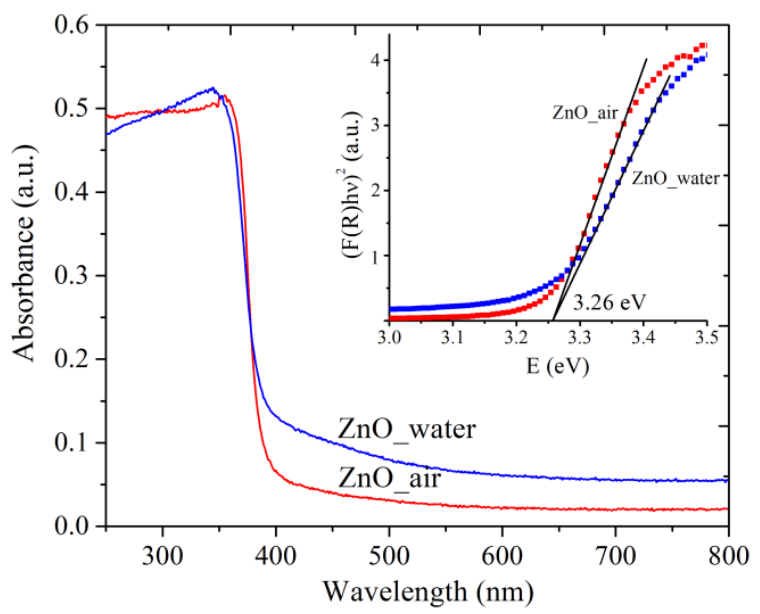

(a)

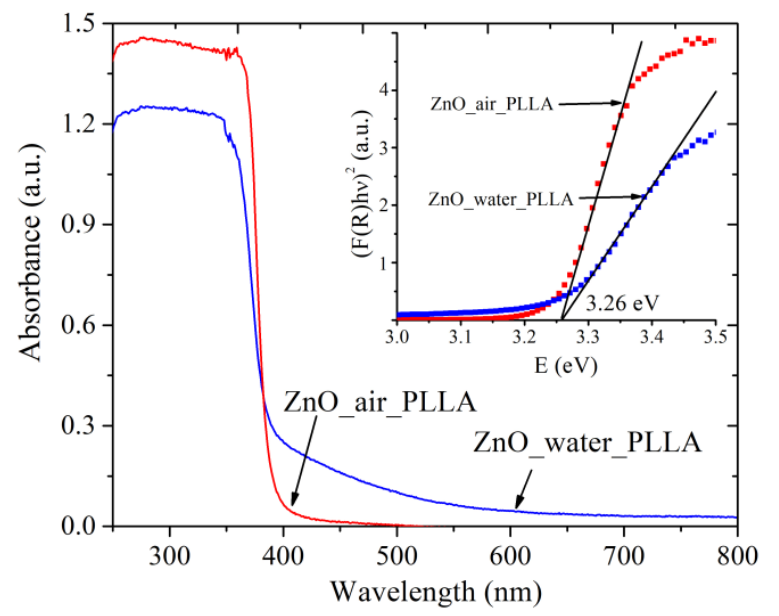

(b)

Figure 5. UV-Vis absorption spectra of powder samples (a) and ZnO-PLLA composites with NPs (b). Insets present how $\mathrm{E}_{\mathrm{g}}$ values were evaluated. Red and blue lines represent data for ZnO NPs produced in air and water, respectively.

The absorption spectra were used to evaluate the bandgap of the materials (see insets in Figure 5). Interestingly, both samples gave the same value of $\sim 3.26 \mathrm{eV}$, in both forms, i.e., as-prepared and after loading onto the PLLA matrix. This value agrees well with literature values for $\mathrm{ZnO}$ nanomaterials, where $E_{\mathrm{g}}$ was reported to be of 3.2-3.4 eV $[1,27,28]$. No quantum-confinement effects are observed as the obtained $\mathrm{ZnO}$ NPs are relatively large (over $10 \mathrm{~nm}$ ).

\subsubsection{Photoluminescence Spectra}

Figure 6 presents the PL spectra of as-prepared samples. Both samples (ZnO_air, red curve, and $\mathrm{ZnO}$ _water, blue curve) are seen to have two bands in their PL spectra: a narrow UV peak around $380 \mathrm{~nm}$ and a wide band in the visible range, with maxima at $612 \mathrm{~nm}$ (red spectrum) and $625 \mathrm{~nm}$ (blue spectrum). The two bands are known to have the exciton (UV) and defect (visible range) nature $[6,15,16,29,30]$. The maximum of defect-related visible PL of sample $\mathrm{ZnO}$ _water is less 
intense and red-shifted compared with that of sample $\mathrm{ZnO}$ _air. The more intense luminescence of sample $\mathrm{ZnO}$ _air is associated with a more defective structure of its NPs. The ZnO NPs prepared in air were shown to be smaller in size and, accordingly, they have a greater number of additional levels available for the radiative recombination of excited electrons. Another reason for a lower PL intensity demonstrated by sample $\mathrm{ZnO} \_w a t e r$ is the presence of -OH groups on the surface of its NPs, as such groups are able to act as quenching centers of luminescence.

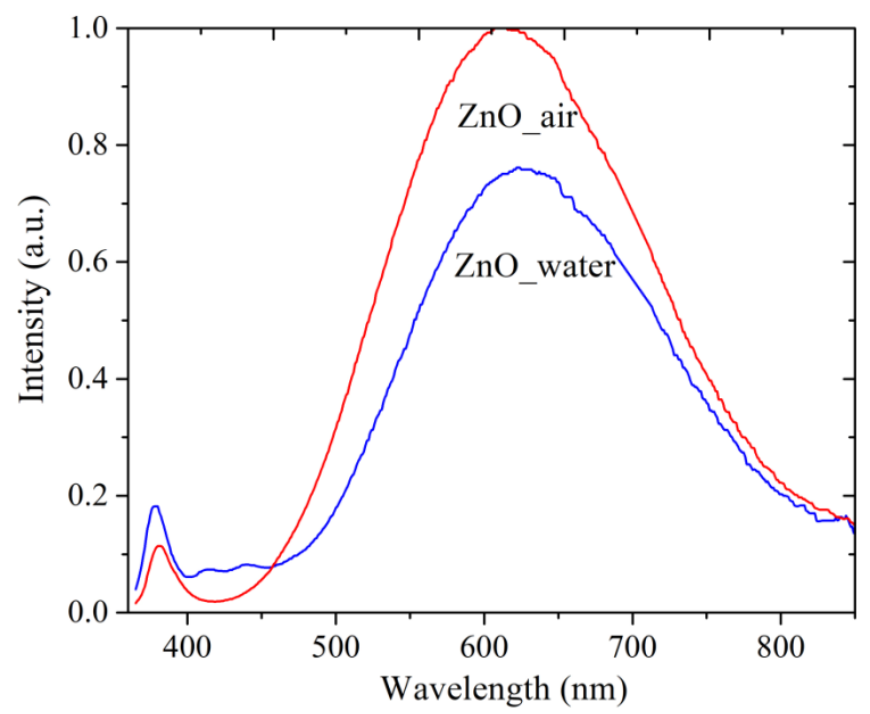

Figure 6. PL spectra of samples PLA-generated in air (red line) and water (blue). Excitation source use had $\lambda_{\mathrm{ex}}=350 \mathrm{~nm}$.

It should be mentioned that there is no full agreement in the literature on interpreting defect-related PL in $\mathrm{ZnO}[15,16,29-32]$. On one hand, the nature of the defects is obviously one of the main factors, while on the other hand, the NP size and morphology have also been reported to play a role $[6,16,31,32]$. Experimentally, it was found that during aging of $\mathrm{ZnO}$ colloids prepared via PLA in liquid, a red-shift of the defect-related PL band occurred [33]. According to [32], the redshift in $\mathrm{ZnO} \mathrm{PL}$ is owing to the presence of defects such as $\mathrm{Zn}_{\mathrm{i}}, \mathrm{O}_{\mathrm{i}}$, and $\mathrm{OH}$ groups, and especially surface defects that are caused by all the peculiarities of PLA in liquid medium as preparation technique. Taking all of this into account, as well as the results of XRD and TEM presented above, one can conclude that the redshift of the PL band of sample $\mathrm{ZnO}$ _water could result from the following two factors: excess of $\mathrm{O}_{\mathrm{i}}$ defects and the rod-shaped morphology of the NPs.

Altogether, the PL spectra in Figure 6 demonstrate that both powders produced by PLA are rich in defects, which should make them attractive for applications in catalysis or as antibacterial nanomaterials.

\subsubsection{IR and Raman Spectra}

The IR spectra of the PLA-prepared samples are presented in Figure 7a. The band observed for both samples (red and blue curves) at $500 \mathrm{~cm}^{-1}$ is characteristic of valence vibrations of the $\mathrm{Zn}-\mathrm{O}$ band [13]. Apart from $\mathrm{Zn}-\mathrm{O}$ vibrations, two wide and intense bands in the range of $3750-2800 \mathrm{~cm}^{-1}$ and $1630-1200 \mathrm{~cm}^{-1}$ are observed for both samples, as well as several less pronounced bands between $\sim 1000$ and $600 \mathrm{~cm}^{-1}$.

Sample ZnO_water demonstrates a wide and featureless band at $\sim 3400 \mathrm{~cm}^{-1}$, similar to what was previously reported by others for ZnO NPs prepared via PLA in water [9]. This band originates from the valent vibrations of $\mathrm{OH}$ groups [34], $\mathrm{OH}$ groups bound to $\mathrm{H}$ atoms [35], and from $\mathrm{Zn}-\mathrm{OH}$ species [9]. In particular, there is a narrow peak at $3740 \mathrm{~cm}^{-1}$ which can be assigned to vibrations of 
isolated $\mathrm{OH}$ group of water on the [10 $\overline{1} 0$ ] facet of $\mathrm{ZnO}$ [34]. The sample prepared in air exhibits more features in this spectral region (see red spectrum in Figure 7a).

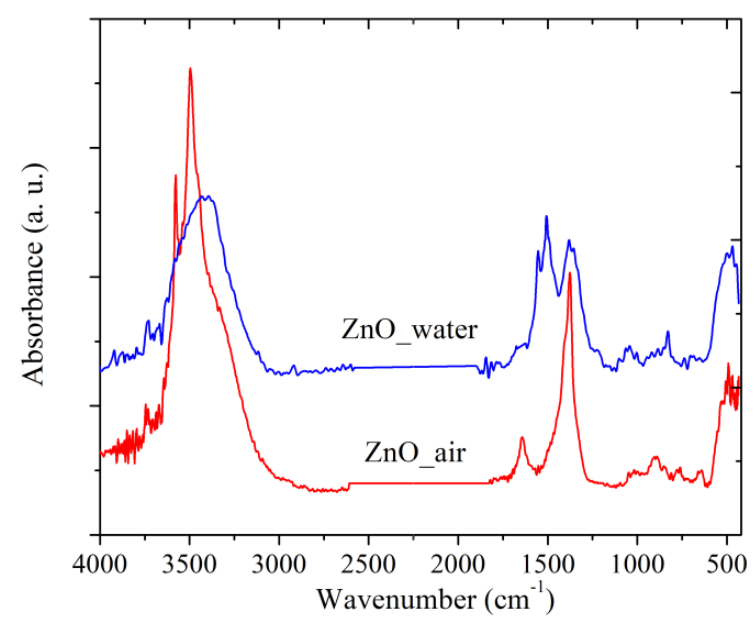

(a)

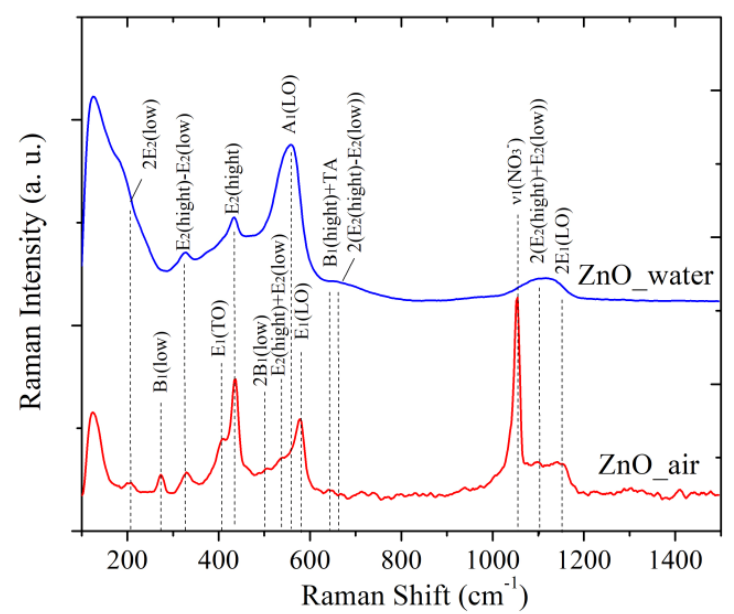

(b)

Figure 7. FTIR (a) and Raman (b) spectra of powder samples. Red and blue lines present data for samples prepared in air and water, respectively.

The second intense band of sample $\mathrm{ZnO} \_$water is believed to be related to carbonate species. For instance, the peak seen at $1372 \mathrm{~cm}^{-1}$ is most likely from the carbonate group of hydrozincite, which is also supported by another band at $1515 \mathrm{~cm}^{-1}$ [30]. The bands at 1049 and $825 \mathrm{~cm}^{-1}$ are also related to the $v_{1}$ and $v_{2}$ vibrations of carbonate groups from hydrozincite [36]. In this region, the sample PLA prepared in water demonstrates a more intense band at $1609 \mathrm{~cm}^{-1}$ which is related to deformational vibrations of intercalated $\mathrm{H}_{2} \mathrm{O}$ molecules. In addition, the vibration band $v_{3}$ of nitrate ions $\left(1374 \mathrm{~cm}^{-1}\right)$ belonging to $\mathrm{Zn}_{5}(\mathrm{OH})_{8}\left(\mathrm{NO}_{3}\right)_{2} \times 2 \mathrm{H}_{2} \mathrm{O}$ is also expected to manifest itself in this region [37].

The Raman spectra of samples are exhibited in Figure $7 \mathrm{~b}$. The wurtzite $\mathrm{ZnO}$ (space group $\mathrm{C}_{6 v}^{4}$ ) is known to demonstrate the following optical modes: polar $A_{1}$ and $E_{1}$ that are active in the IR and Raman ranges, doubly degenerate $E_{2}$ mode with frequencies $E_{2}(l o w)$ and $E_{2}$ (hight), and inactive "silent" $\mathrm{B}_{1}$ mode. The spectrum of sample $\mathrm{ZnO}$ _air (red line in Figure $7 \mathrm{~b}$ ) is seen to have more features, demonstrating, e.g., bands at 205, 408, and $437 \mathrm{~cm}^{-1}$, which are related to the main optical vibrations of the crystal lattice $2 \mathrm{E}_{2}(\mathrm{low})$, transversal $\mathrm{E}_{1}(\mathrm{TO})$ and $\mathrm{E}_{2}$ (hight) vibrations, respectively. Since sample ZnO_air exhibits a more pronounced band $\mathrm{E}_{2}$ (hight) at $437 \mathrm{~cm}^{-1}$, this implies that its NPs are better crystallized than those obtained in water (compare red and blue curves in Figure $7 \mathrm{~b}$ ). The band at $577 \mathrm{~cm}^{-1}$ can be assigned to either the $A_{1}(L O)$ or to $E_{1}(L O)$ lateral vibrations. This spectral range can also be linked to a mixed quasi-LO mode with $\mathrm{E}_{1}$ and $\mathrm{A}_{1}$ symmetries that are closely related to the presence of defects [38]. Because PLA-generated NPs are known to be rich in defects $[7,9,15]$, it is safe to assume that the peak at $577 \mathrm{~cm}^{-1}$ originates from the $\mathrm{E}_{1}(\mathrm{LO})$ mode. Finally, the bands below $150 \mathrm{~cm}^{-1}$ are hard to identify and are most likely to be related to defects as well.

The distinctive feature of sample $\mathrm{ZnO}$ _water (blue spectrum in Figure $7 \mathrm{~b}$ ) is its wide dominating $\mathrm{A}_{1}(\mathrm{LO})$ mode around $560 \mathrm{~cm}^{-1}$, which is characteristic of lattice vibrations parallel to the growth direction. This agrees well with the above presented TEM images where rod-like morphology of the NPs prepared in water was revealed.

In agreement with the XRD results, where the presence of ZHN phase was revealed, the Raman spectrum of sample $\mathrm{ZnO}$ _air also demonstrates additional modes of this phase (see peaks at 273, 506 and $639 \mathrm{~cm}^{-1}$ in Figure $7 \mathrm{~b}$ ) that correspond to the $\mathrm{B}_{1}(\mathrm{low}), 2 \mathrm{~B}_{1}(\mathrm{low})$ and $\mathrm{B}_{1}$ (hight)+TA vibrations, respectively. In addition, the intense peak at $1050 \mathrm{~cm}^{-1}$ belonging to $v_{1}\left(\mathrm{NO}_{3}{ }^{-}\right)$vibrations of nitrate ions is also observed [39]. The weak band at $713 \mathrm{~cm}^{-1}$ is also due to the nitrate ions, presening its 
$v_{4}\left(\mathrm{NO}_{3}{ }^{-}\right)$vibration mode. Finally, the wide band between 1050 and $1150 \mathrm{~cm}^{-1}$ observed for both samples is related to multi-phonon vibrations of $\mathrm{ZnO}$ crystal lattice.

Thus, the FTIR and Raman spectroscopic data correlate well with the above-presented XRD, PL and TEM results. In particular, they confirm: (i) the presence of ZHN phase in sample ZnO_air; (ii) the rod-shaped morphology of NPs generated in water; and (iii) the highly defective nature of both samples as previously revealed by their PL spectra.

\subsection{Zeta Potential}

The value of $\zeta$-potential is known to determine the stability of a colloidal solution, the system being stable when it is over $\pm 30 \mathrm{mV}$. Information on the surface charge of NPs makes it possible to predict their interaction with bacterium cell membrane, the strength of which also depends on the bacteria type. Figure 8 exhibits the values of $\zeta$-potential of the two samples dispersed in water as they were titrated with $\mathrm{KOH}$ solution to determine their $\mathrm{pH}_{\text {iep. }}$.

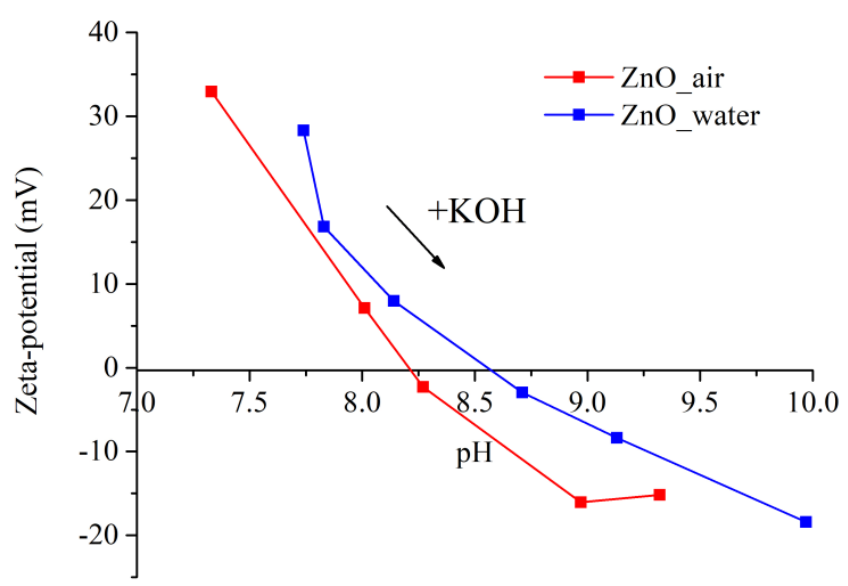

Figure 8. Zeta potential of NPs evaluated at different $\mathrm{pH}$ values. Blue and red symbols stand for samples prepared in water and air, respectively.

It can be clearly seen in Figure 8 that the $\zeta$-potential values of both samples are positive, being $+33 \mathrm{mV}$ (red curve) and $+28 \mathrm{mV}$ (blue curve) for NPs produced in air and water, respectively. Because of the larger value of its $\zeta$-potential, the dispersion of sample $\mathrm{ZnO}$ _air is more stable in water, which is in agreement with the above discussion in Section 3.2.2. While the initial $\mathrm{pH}$ of water was $\sim 6.3$, the values were shifted to $\mathrm{pH} 7.3$ (red curve) and pH 7.8 (blue curve) when the tested powders were dispersed. The values of the isoelectric point obtained for the dispersions were found to be in the basic range, agreeing well with the literature [40]. Thus, the surface of both types of NPs is positively charged at $\mathrm{pH}$ below this value, as protons from water are transferred onto the NPs and form surface $\mathrm{Zn}-\mathrm{OH}_{2}{ }^{+}$groups [41]. The difference between the two curves in Figure 8, and thus in the values of $\mathrm{pH}_{\text {iep }}$, implies that the surface chemistry of the two powders prepared in different media is different, which was previously revealed by both IR and Raman spectroscopy measurements.

As mentioned previously in Section 3.2.2, the positive $\zeta$-potential of both laser-generated samples is an important factor that contributed to good surface adhesion and uniform deposition of their NPs onto PLLA scaffolds, the latter being negatively charged.

\subsection{Antibacterial Activity}

Table 2 shows the results of antibacterial tests obtained on the model PLLA tissues loaded with the two laser-generated $\mathrm{ZnO}$ powders. It can be clearly seen that both samples demonstrated good antibacterial activity towards S. aureus (A > 3, according to ISO 20743: 2013), with the activity of sample ZnO_air_PLLA being significantly higher. The latter finding could be explained by either the 
larger specific surface area and more defective structure of its NPs (with smaller sizes) or their surface chemistry; both assumptions require additional studies.

Table 2. Antibacterial activity of prepared samples towards S. aureus and E. coli.

\begin{tabular}{|c|c|c|c|}
\hline \multirow{2}{*}{ Sample } & \multicolumn{2}{|c|}{ The Level of Growth } & \multirow{2}{*}{$\begin{array}{l}\text { Antibacterial Activity } \\
\qquad(A=F-G)\end{array}$} \\
\hline & Control $F=\lg C_{t}-\lg C_{0}$ & Sample $G=\lg T_{t}-\lg T_{0}$ & \\
\hline \multicolumn{4}{|c|}{ S. aureus (+) } \\
\hline $\begin{array}{c}\text { ZnO_water_PLLA } \\
\text { ZnO_air_PLLA }\end{array}$ & +3.18 & $\begin{array}{l}-1.62 \\
-2.48\end{array}$ & $\begin{array}{l}+4.80 \\
+5.66\end{array}$ \\
\hline \multicolumn{4}{|c|}{ E. coli $(-)$} \\
\hline $\begin{array}{c}\text { ZnO_water_PLLA } \\
\text { ZnO_air_PLLA }\end{array}$ & +2.95 & $\begin{array}{l}+1.53 \\
+1.67\end{array}$ & $\begin{array}{l}+1.42 \\
+1.28 \\
\end{array}$ \\
\hline
\end{tabular}

At the same time, the antibacterial activities of both samples towards E. coli, though exhibiting strong inhibitory effect, were found to be very close to each other, and lower than in the case of S. aureus. This agrees well with our previous results, reported for PLA-prepared ZnO NPs deposited onto cotton fabrics [10]. The observed difference in bactericidal action between the two strains tested is believed to be caused by their wall structures. While the S. aureus is known to be protected by its wall made of peptidoglycan (which has teichoic and lipoteichoic acids), the E. coli bacteria have an outer membrane that has a more complex chemical composition and contains lipopolysaccharide surrounded by a thin layer of peptidoglycan. The latter more complex structure provides the E. coli higher resistivity. It should be noted, however, that for wound dressing, it is the bactericidal action against the $S$. aureus that is of higher importance than that against $E$. coli.

There are several models explaining the antibacterial action of ZnO NPs. One possible mechanism proposed suggests that their bactericidal effect can be related to reactive oxygen species generated by such particles [42]. It cannot be excluded that the inhibiting action could also be due to the $\mathrm{Zn}^{2+}$ cations that are released as a result of partial dissolution of ZnO NPs [43] and result in membrane dysfunction [44] and NP internalization with the bacterium surface [45]. More details on possible bactericidal mechanisms of $\mathrm{ZnO}$ NPs can be found elsewhere $[2,46]$.

The antibacterial tests carried out in this study confirm a high bactericidal potential of nano-sized $\mathrm{ZnO}$ loaded onto biodegradbalbe PLLA matrix as a model dressing for wound treatment. Besides, the novel $\mathrm{ZnO}$ powder produced via PLA in air was found to demonstrate higher antibacterial activity, which can be explained by its more uniform distribution over matrix fibers and by a larger specific surface area of its NPs.

\section{Conclusions}

In this study, we prepared $\mathrm{ZnO}$ nanoparticles (NPs) by ablating $\mathrm{Zn}$ target with nanosecond pulsed laser in water and air media and compared their properties. It was found that the NPs produced in air were of spherical shape, while their counterparts produced in water were somewhat larger and rod-shaped. Both samples were based on hexagonal wurtzite $\mathrm{ZnO}$ phase, while because of interaction with atmospheric nitrogen, the sample generated in air also had some fraction of monoclinic zinc hydroxynitrate.

The NPs prepared in air were more stable in colloid (having zeta potential $\zeta>30 \mathrm{mV}$ ) and demonstrated better dispersibility in water. After characterization by various structural and spectroscopic techniques, both powders were loaded onto polymeric matrix of biodegradable poly L-lactic acid, thus forming model biomedical composite materials for wound dressing. The antibacterial behavior of the two model dressings was tested against $S$. aureus and E. coli strains, showing promising bactericidal action against the former. 
Upon comparing ZnO NPs produced in water and air, this work demonstrates that the latter NPs had better dispersibility in water, while their antibacterial behavior was at least comparable with that of the former ones. Thus, when it comes to using ZnO NPs as powders, for example to disperse them and load them onto/into biodegradable polymer matrix, nanoparticles produced via laser ablation in air should be considered as real and promising alternatives to their counterparts prepared in water.

Author Contributions: Conceptualization, V.A.S. and S.A.K.; methodology, D.A.G.; validation, A.A.A. and N.M.; investigation, E.A.G., D.A.G., I.N.L. and A.L.N.; visualization, E.A.G.; writing and editing, E.A.G., V.A.S. and S.A.K.

Funding: This research was funded by the Tomsk State University competitiveness improvement program, and by the Japan Society for the Promotion of Science (JSPS, grant no. 16K04904). D.A.G was supported by the scholarship program of the President of the Russian Federation for young scientists and post-graduate students (SP-2018 Competition).

Acknowledgments: The authors thank T.S. Kharlamova for zeta potential measurements and M.A. Gerasimova for photoluminescence measurements. Characterization was carried out using equipment of the Tomsk Regional Common Use Centre, Tomsk State University.

Conflicts of Interest: The authors declare no conflict of interest.

\section{References}

1. Özgür, Ü.; Alivov, Y.I.; Liu, C.; Teke, A.; Reshchikov, M.A.; Doğan, S.; Avrutin, V.; Cho, S.J.; Morkoç, H. A comprehensive review of $\mathrm{ZnO}$ materials and devices. J. Appl. Phys. 2005, 98, 041301. [CrossRef]

2. Król, A.; Pomastowski, P.; Rafińska, K.; Railean-Plugaru, V.; Buszewski, B. Zinc oxide nanoparticles: Synthesis, antiseptic activity and toxicity mechanism. Adv. Colloid Interface Sci. 2017, 249, 37-52. [CrossRef] [PubMed]

3. Gomez, J.L.; Tigli, O. Zinc oxide nanostructures: From growth to application. J. Mater. Sci. 2013, 48, 612-624. [CrossRef]

4. Mintcheva, N.; Aljulaih, A.A.; Wunderlich, W.; Kulinich, S.A.; Iwamori, S. Laser-ablated ZnO nanoparticles and their photocatalytic activity toward organic pollutants. Materials 2018, 11, 1127. [CrossRef] [PubMed]

5. Kondo, T.; Sato, Y.; Kinoshita, M.; Shankar, P.; Mintcheva, N.; Honda, M.; Iwamori, S.; Kulinich, S.A. Room temperature ethanol sensor based on ZnO prepared via laser ablation in water. Jpn. J. Appl. Phys. 2017, 56, 080304. [CrossRef]

6. Kulinich, S.A.; Kondo, T.; Shimizu, Y.; Ito, T. Pressure effect on ZnO nanoparticles prepared via laser ablation in water. J. Appl. Phys. 2013, 113, 033509. [CrossRef]

7. Zeng, H.; Du, X.W.; Singh, S.C.; Kulinich, S.A.; Yang, S.; He, J.; Cai, W. Nanomaterials via laser ablation/ irradiation in liquid: A review. Adv. Funct. Mater. 2012, 22, 1333-1353. [CrossRef]

8. Liang, C.; Shimizu, Y.; Masuda, M.; Sasaki, T.; Koshizaki, N. Preparation of layered zinc hydroxide/surfactant nanocomposite by pulsed-laser ablation in a liquid medium. Chem. Mater. 2004, 16, 963-965. [CrossRef]

9. Yan, Z.; Chrisey, D.B. Pulsed laser ablation in liquid for micro-/nanostructure generation. J. Photochem. Photobiol. C 2012, 13, 204-223. [CrossRef]

10. Svetlichnyi, V.; Shabalina, A.; Lapin, I.; Goncharova, D.; Nemoykina, A. ZnO nanoparticles obtained by pulsed laser ablation and their composite with cotton fabric: Preparation and study of antibacterial activity. Appl. Surf. Sci. 2016, 372, 20-29. [CrossRef]

11. Yang, X.C.; Riehemann, W.; Dubiel, M.; Hofmeister, H. Nanoscaled ceramic powders produced by laser ablation. Mater. Sci. Eng. B 2002, 95, 299-307. [CrossRef]

12. Niu, K.Y.; Kulinich, S.A.; Yang, J.; Zhu, A.L.; Du, X.W. Galvanic replacement reactions of active-metal nanoparticles. Chem. Eur. J. 2012, 18, 4234-4241. [CrossRef] [PubMed]

13. Yu, H.; Li, H.; Wang, Y.; Cui, L.; Liu, S.; Yang, J. Brief review on pulse laser propulsion. Opt. Laser Technol. 2018, 100, 57-74. [CrossRef]

14. Gondal, M.A.; Drmosh, Q.A.; Yamani, Z.H.; Saleh, T.A. Synthesis of ZnO nanoparticles by laser ablation in liquid and their annealing transformation into ZnO nanoparticles. Appl. Surf. Sci. 2009, 256, 298-304. [CrossRef]

15. Goto, T.; Honda, M.; Kulinich, S.A.; Shimizu, Y.; Ito, T. Defects in ZnO nanoparticles laser-ablated in water-ethanol mixtures at different pressures. Jpn. J. Appl. Phys. 2015, 54, 070305. [CrossRef] 
16. Honda, M.; Goto, T.; Owashi, T.; Rozhin, A.G.; Yamaguchi, S.; Ito, T.; Kulinich, S.A. ZnO nanorods prepared via ablation of Zn with millisecond laser in liquid media. Phys. Chem. Chem. Phys. 2016, 18, 23628-23637. [CrossRef] [PubMed]

17. Janotti, A.; Van de Walle, C.G. Fundamentals of zinc oxide as a semiconductor. Rep. Prog. Phys. 2009, 72, 126501. [CrossRef]

18. Svetlichnyi, V.A.; Shabalina, A.V.; Lapin, I.N.; Goncharova, D.A.; Kharlamova, T.S.; Stadnichenko, A.I. Comparative study of magnetite nanoparticles obtained by pulsed laser ablation in water and air. Appl. Surf. Sci. 2019, 467-468, 402-410. [CrossRef]

19. Albertsson, A.-C.; Varma, I.K. Degradable aliphatic polyesters. In Advances in Polymer Science; Albertsson, A.-C., Ed.; Springer: Berlin, Germany, 2002; Volume 157, pp. 1-40. ISBN 978-3-642-10576-0.

20. Badaraev, A.D.; Nemoykina, A.L.; Bolbasov, E.N.; Tverdokhlebov, S.I. PLLA scaffold modification using magnetron sputtering of the copper target to provide antibacterial properties. Resour.-Effic. Technol. 2017, 3, 204-2011. [CrossRef]

21. López, R.; Gómez, R. Band-gap energy estimation from diffuse reflectance measurements on sol-gel and commercial $\mathrm{TiO}_{2}$ : A comparative study. J. Sol-Gel Sci. Technol. 2012, 61, 1-7. [CrossRef]

22. ISO 20743:2013. Textiles-Determination of Antibacterial Activity of Textile Products, 2nd ed.; ISO: Geneva, Swizerland, 2013.

23. Roske, C.W.; Lefler, J.W.; Müller, A.M. Complex nanomineral formation utilizing kinetic control by PLAL. J. Colloid Interface Sci. 2017, 489, 68-75. [CrossRef] [PubMed]

24. Ishikawa, Y.; Shimizu, Y.; Sasaki, T.; Koshizaki, N. Preparation of zinc oxide nanorods using pulsed laser ablation in water media at high temperature. J. Colloid Interface Sci. 2006, 300, 612-615. [CrossRef] [PubMed]

25. Panda, D.; Tseng, T.Y. One-dimensional ZnO nanostructures: Fabrication, optoelectronic properties, and device applications. J. Mater. Sci. 2013, 48, 6849-6877. [CrossRef]

26. Croisier, F.; Aqil, A.; Malherbe, C.; Gilbert, B.; Detrembleur, C.; Jerome, C. Charged Poly(D,L-lactide) nanofibers: Towards customized surface properties. Macromol. Symp. 2011, 309-310, 20-27. [CrossRef]

27. Pearton, S.J.; Norton, D.P.; Ip, K.; Steiner, T.; Heo, Y.W. Recent advances in processing of ZnO. J. Vac. Sci. Technol. B 2004, 22, 932-948. [CrossRef]

28. Yi, G.C.; Wang, C.; Park, W. ZnO nanorods: Synthesis, characterization and applications. Semicond. Sci. Technol. 2005, 20, 22-34. [CrossRef]

29. Vempati, S.; Mitra, J.; Dawson, P. One-step synthesis of $\mathrm{ZnO}$ nanosheets: A blue-white fluorophore. Nanoscale Res. Lett. 2012, 7, 470. [CrossRef]

30. Mao, J.; Chen, X.; Ling, T.; Du, X. Strong blue emission from zinc hydroxide carbonate nanosheets. J. Lumin. 2016, 177, 242-248. [CrossRef]

31. Anantachaisilp, S.; Smith, S.M.; Ton-That, C.; Pornsuwan, S.; Moo, A.R.; Nenstiel, C.; Hoffmann, A.; Phillips, M.R. Nature of red luminescence in oxygen treated hydrothermally grown zinc oxide nanorods. J. Lumin. 2015, 168, 20-25. [CrossRef]

32. Kurudirek, S.V.; Pradel, K.C.; Summers, C.J. Low-temperature hydrothermally grown 100 mm vertically well-aligned ultralong and ultradense ZnO nanorod arrays with improved PL property. J. Alloys Compd. 2017, 702, 700-709. [CrossRef]

33. Svetlichnyi, V.A.; Lapin, I.N. Structure and properties of nanoparticles fabricated by laser ablation of Zn metal targets in water and ethanol. Russ. Phys. J. 2013, 56, 581-587. [CrossRef]

34. Wöll, C. The chemistry and physics of zinc oxide surfaces. Prog. Surf. Sci. 2007, 82, 55-120. [CrossRef]

35. Barsukov, D.V.; Subbotina, I.R. IR-study of hydrated surface of oxide photocatalysts. Russ. Chem. Bull. 2017, 66, 1847-1853. [CrossRef]

36. Japi, D.; Bitenc, M.; Marinšek, M.; Orel, Z.C. The impact of nano-milling on porous ZnO prepared from layered zinc hydroxide nitrate and zinc hydroxide carbonate. Mater. Res. Bull. 2014, 60, 738-745. [CrossRef]

37. Li, P.; Xu, Z.P.; Hampton, M.A.; Vu, D.T.; Huang, L.; Rudolph, V.; Nguyen, A.V. Control preparation of zinc hydroxide nitrate nanocrystals and examination of the chemical and structural stability. J. Phys. Chem. C 2012, 116, 10325-10332. [CrossRef]

38. Klingshirn, C.F.; Meyer, B.K.; Waag, A.; Hoffmann, A.; Geurts, J. Zinc oxide: From fundamental properties towards novel applications. In Springer Series in Materials Science; Hull, R., Jagadish, C., Osgood, R.M., Jr., Parisi, J., Wang, Z., Warlimont, H., Eds.; Springer: New York, NY, USA, 2010; Volume 120, pp. 233-266. ISBN 978-3-642-10576-0. 
39. Liu, X.; Wang, C.; Liu, X.; Ouyang, L.; You, Z.; Lu, Y.; Chen, X. Understanding the factors that control the formation and morphology of $\mathrm{Zn}_{5}(\mathrm{OH})_{8}\left(\mathrm{NO}_{3}\right)_{2} \times 2 \mathrm{H}_{2} \mathrm{O}$ through hydrothermal route. J. Nanomater. 2013, 2013, 938370. [CrossRef]

40. Degen, A.A.; Kosec, M. Effect of $\mathrm{pH}$ and impurities on the surface charge of zinc oxide in aqueous solution. J. Eur. Ceram. Soc. 2000, 20, 667-673. [CrossRef]

41. Lee, K.M.; Lai, C.W.; Ngai, K.S.; Juan, J.C. Recent developments of zinc oxide based photocatalyst in water treatment technology: A review. Water Res. 2016, 88, 428-448. [CrossRef] [PubMed]

42. Xia, T.; Kovochich, M.; Liong, M.; Mädler, L.; Gilbert, B.; Shi, H.; Yeh, J.I.; Zink, J.I.; Nel, A.E. Comparison of the mechanism of toxicity of zinc oxide and cerium oxide nanoparticles based on dissolution and oxidative stress properties. ACS Nano 2008, 2, 2121-2134. [CrossRef] [PubMed]

43. Li, M.; Pokhrel, S.; Jin, X.; Mädler, L.; Damoiseaux, R.; Hoek, E.M. Stability, bioavailability, and bacterial toxicity of $\mathrm{ZnO}$ and iron-doped $\mathrm{ZnO}$ nanoparticles in aquatic media. Environ. Sci. Technol. 2011, 45, 755-761. [CrossRef]

44. Kavitha, T.; Gopalan, A.I.; Lee, K.-P.; Park, S.-Y. Glucose sensing, photocatalytic and antibacterial properties of graphene-ZnO nanoparticle hybrids. Carbon 2012, 50, 2994-3000. [CrossRef]

45. Huang, Z.; Zheng, X.; Yan, D.; Yin, G.; Liao, X.; Kang, Y.; Yao, Y.; Huang, D.; Hao, B. Toxicological effect of $\mathrm{ZnO}$ nanoparticles based on bacteria. Langmuir 2008, 24, 4140-4144. [CrossRef] [PubMed]

46. Sirelkhatim, A.; Mahmud, S.; Seeni, A.; Kaus, N.H.M.; Ann, L.C.; Bakhori, S.K.M.; Hasan, H.; Mohamad, D. Review on zinc oxide nanoparticles: Antibacterial activity and toxicity mechanism. Nano-Micro Lett. 2015, 7 , 219-242. [CrossRef] [PubMed]

(C) 2019 by the authors. Licensee MDPI, Basel, Switzerland. This article is an open access article distributed under the terms and conditions of the Creative Commons Attribution (CC BY) license (http://creativecommons.org/licenses/by/4.0/). 